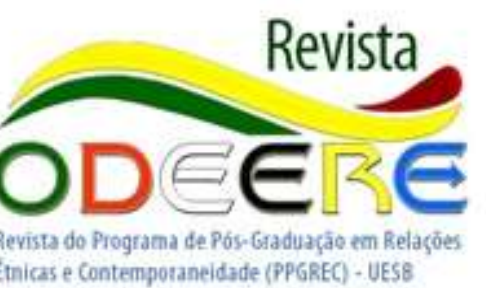

\section{Comunidade Quilombola de Velame/BA: história, lutas, superações e adiamentos}

\section{Quilombola} Community of Velame/BA: history, struggles, overcoming and
postponing

\author{
Silvano da Conceição \\ iD http://orcid.org/0000-0002-3577-2268 \\ Universidade Estadual do Sudoeste da Bahia \\ silconceicao5@gmail.com
}

DOI: 10.22481/odeere.v5i9.6661

RESUMO: No presente artigo a proposta foi discutir alguns processos que tem marcado a história da Comunidade Quilombola de Velame, localizada a $54 \mathrm{~km}$ do município de Vitória da Conquista/Bahia. A metodologia utilizada foi a qualitativa, com a utilização da técnica de entrevistas (idosos, adultos e jovens) e pesquisa de campo. Cotejamos essas informações com as encontradas no Relatório Antropológico da Comunidade Quilombola de
Velame. O processo de expulsão de suas terras e o posterior regresso, deixaram profundas marcas na comunidade, uma vez que isso interferiu diretamente na dimensão territorial e na quantidade de famílias que residiam na mesma. A análise de todo material coletado revelou que a incorporação da identidade quilombola é indicador de uma leitura estratégica da comunidade, tanto para acessar políticas públicas, como para dar início ao processo de titulação de suas terras. Notamos ainda que o Estado brasileiro continua a viver um enorme dilema, em se tratando da garantia dos direitos dos povos tradicionais, visto os seus operadores jurídico e político parecem, na maioria das vezes, inoperantes ante a necessidade de dar celeridade aos processos de titulação das terras quilombolas.

Palavras-chave: comunidade quilombola; desenvolvimento social; políticas públicas; território.

ABSTRACT: In this article the proposal was to discuss some processes that have marked the history of the Quilombola de Velame Community, located $54 \mathrm{~km}$ from the municipality of Vitória da Conquista / Bahia. The methodology used was qualitative, with the use of the technique of interviews (elderly, adults and young people) and field research. We compared this information with that found in the Anthropological Report of the Quilombola de Velame Community. The process of eviction from their lands and the subsequent return, left profound marks on the community, since this directly interfered in the territorial dimension and in the number of families that lived in it. The analysis of all collected material revealed that the incorporation of the quilombola identity is an indicator of a strategic reading of the community, both to access public policies and to start the process of titling their lands. We also note that the Brazilian State continues to live an enormous dilemma, in terms of guaranteeing the rights of traditional peoples, given that its legal and political operators seem, in most cases, inoperative in view of the need to speed up the titling processes of quilombola lands.

Keywords: quilombola community; social development; public policies; territory. 


\section{FORMAÇÃO ORIGINAL, LUTAS E TERRITÓRIO ATUAL1}

Eles contavam também da comunidade, de quando eles veio praqui, aqui era só mato, meu bisavô mais meu avô que fez a abertura (né), começou a fazer abertura; aí foi fazendo roça. Vou falar primeiro do meu bisavô. O nome dele era Manoel Fortunato e o meu avô, que era Benedito Fortunato. [...] Quando ele veio pra qui, meu bisavô, ele veio viúvo e deixou um bocado de filhos, que eles morava pro lado do Furadinho² pra lá, lá perto de Conquista. Aí naquele tempo ele deixou casa pra maior parte dos filhos, ele só veio pra cá com dois filhos, que é o Benedito Fortunato e mais uma filha que eu não sei o nome não? .

A história da Comunidade Quilombola de Velame, localizada a $54 \mathrm{~km}$ do município de Vitória da Conquista/Bahia, teve início entre o final da década de 1870 e início da década de 1890, quando Benedito Fortunato da França, notando o crescimento de sua família, resolveu procurar outro local para viver. Ainda de acordo com o Relatório Antropológico da Comunidade Quilombola de Velame (2009), as terras da Comunidade foram compradas por Benedito Fortunato da França com o dinheiro que conseguiu ao vender a sua porção de terras na Comunidade Quilombola do Furadinho4.

A vida razoavelmente tranquila da comunidade, em relação ao território, começou a sofrer alguns abalos após o falecimento (em 1937), aos 62 anos de idade, de Maria Senhoria de Jesus, esposa de Benedito Fortunato da França. Após esse ocorrido, em 1938 Benedito Fortunato fez uma divisão judicial do território, entre ele e os seus treze filhos, e depois mudou-se para a comunidade Pau de Espinhos (Belo Campo), casando-se novamente e tendo mais dois filhos. Para pagar as custas do processo acabou vendendo seis (6) alqueires do território de Velame para Josefino Ferraz de Oliveira que mudou-se com sua família para esse

\footnotetext{
${ }^{1}$ Este item do texto foi elaborado a partir das informações contidas no RELATÓRIO ANTROPOLÓGICO DA COMUNIDADE QUILOMBOLA DE VELAME (2009) e nas entrevistas que realizamos junto aos moradores/as da comunidade.

${ }^{2}$ A Comunidade do Furadinho se encontra a $18 \mathrm{~km}$ da Comunidade Quilombola de Velame e a, aproximadamente, $36 \mathrm{~km}$ da cidade de Vitória da Conquista.

3Trecho da Entrevista com Informante idoso, Comunidade de Velame, 2015.

${ }^{4}$ Antes mesmo de deixar essa comunidade Manuel Fortunato da Silva (pai de Benedito Fortunato) já havia feito a partilha das terras entre todos os seus herdeiros. Sobre a compra das terras de Velame a equipe de elaboração do RTID/Velame não localizou o respectivo processo.
} 
pedaço de terra 5 .

Quando o meu avô era vivi era tudo diferente, mas foi chegando o tempo em que meu avô ficou viúvo. Quando ele ficou viúvo, ele já tinha os fios já criado, ele começou a dizer que entregava as terras pros filhos né. E foi nessa trajetória que o negócio bagunçou muito a comunidade, porque ele saiu daqui, vendeu um pedacinho dessa terra quase lá na pista, pra lá, pra um fazendeiro e esse fazendeiro quase tomou conta das terras quase todinha, né, dos filhos. E aí ficou a encrenca mais os filhos, ele (avô) saiu pra outro lugar que arrumou uma mulher e aí os filhos ficou bagunçado e o fazendeiro dizendo que tinha comprado tudo do meu avô, sendo que não comprou né, a terra. E isso ficou cerca de uns 50 anos e até hoje ainda tá essa bagunçab.

O trecho nos aponta o início do que seria o processo de expropriação territorial vivenciado pelos moradores da comunidade, pois a venda de uma pequena parte do território serviu como "gatilho" para que o fazendeiro iniciasse o processo de expropriação de boa parte das terras pertencentes à mesma. Grosso modo, podemos afirmar que o processo de expropriação do território da Comunidade de Velame iniciou-se a partir de três atitudes do seu fundador: 1) divisão judicial das terras entre os seus filhos; 2) venda de uma parte das terras pra alguém externo à Comunidade Velame e; 3) mudança do fundador para a comunidade Pau de Espinhos, em Belo Campo.

De 1938 a 1940, o território da Comunidade Quilombola de Velame não sofreu alterações, o que permitiu à mesma a continuidade do cultivo de suas roças, a criação de animais, a realização de suas festividades tradicionais e a extração de alguns produtos das matas de cipó. Porém, com a notícia do falecimento, em 1940, de Benedito Fortunato da França, a pessoa que havia comprado seis alqueires de terra de Velame, passou a afirmar que havia comprado mais 40 alqueires. Quando foi exigido que apresentasse o documento de tal transação (compra e venda) a pessoa conseguiu comprovar a compra de apenas seis alqueires?. 


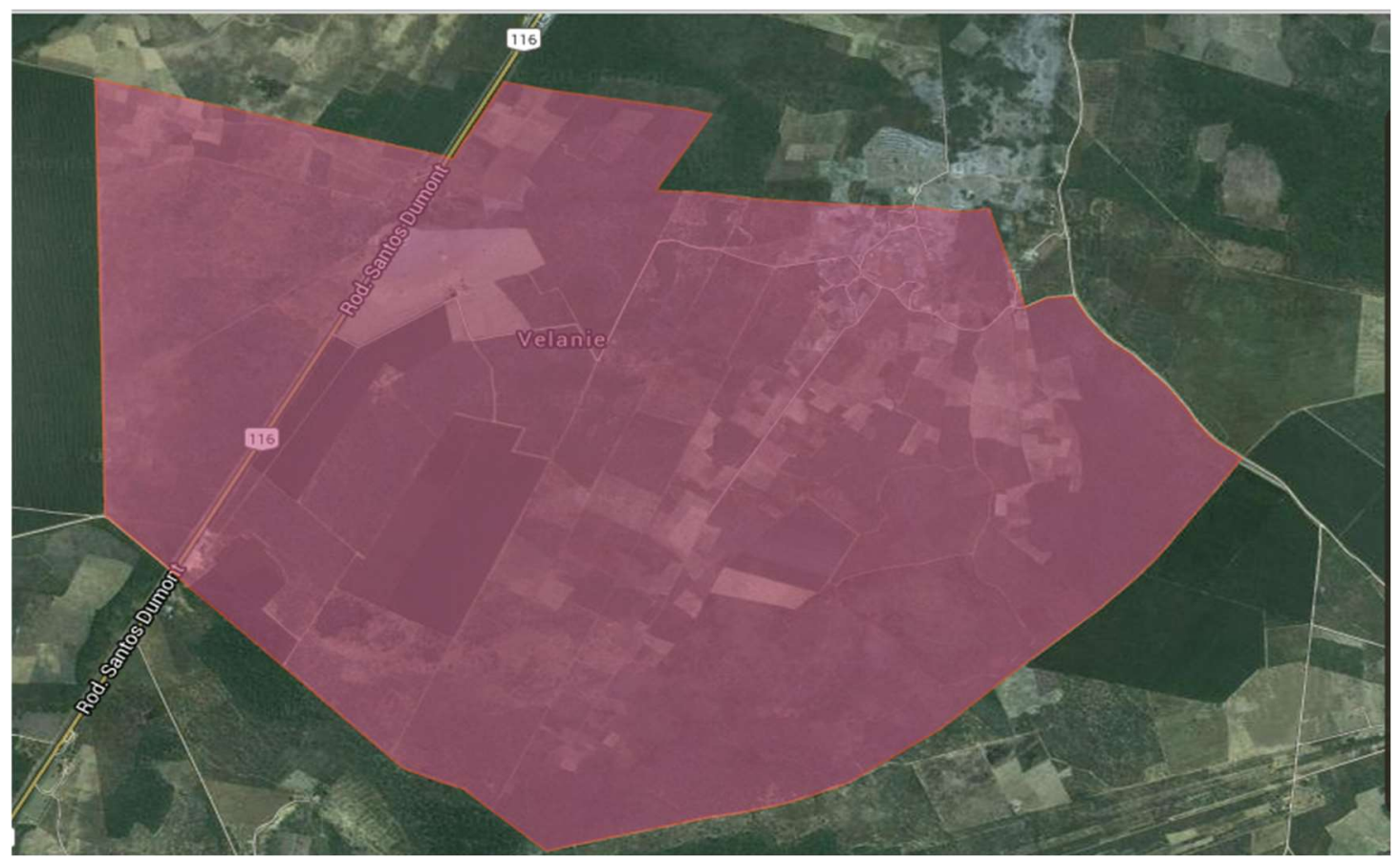

Figura 1: Dimensão Territorial da Comunidade Quilombola de Velame. Município de Vitória da Conquista, Bahia.

Fonte: http://monitoramento.seppir.gov.br/paineis/pbq/mapas.vm? type=quilombola\&id=159

A pretexto de comprovar, no Cartório de Registro de Imóveis da Comarca de Vitória da Conquista, a aquisição de seis alqueires de terra, o fazendeiro Josefino Ferraz conseguiu convencer, entre 1940-1945, Máxima de Jesus França - filha de Benedito Fortunato - a the emprestar a documentação da propriedade de seu Benedito, que simplesmente desapareceu. Com esse documento em mãos, Josefino o entregou ao seu primo (Dário Ferraz), que trabalhava no referido cartório e, passados alguns anos, o mesmo apareceu na Comunidade de Velame portando o registro da compra de mais quarenta alqueires de terras, além dos seis dos quais o fazendeiro já possuía documentação. No momento em que cercava "suas terras" Josefino Ferraz ampliou a área que constava no documento de posse: ao invés de cercar 46, ampliou-a para 60 alqueires ${ }^{8}$.

As consequências desse processo de expropriação de suas terras foram desastrosas para toda a comunidade, uma vez que o cercamento da propriedade, além de ter promovido uma aglomeração de famílias nas terras que restaram (claramente insuficientes pra atender às necessidades da comunidade), 
ainda passou a dificultar o deslocamento dos quilombolas até Veredinha, local onde essas pessoas acessavam diversos serviços, tais como armazém, escola, farmácia, posto de saúde, telefone público, igreja e transporte para Vitória da Conquista e outras cidades. Também ficou comprometida a realização de inúmeras festividades, tais como Samba de Presépio, o Terno de Reis, o Levanta Bandeira e a Reza de Santo Antônio, os festejos de São João, etc., uma vez que toda a estrutura para a realização das mesmas estava nas terras que a comunidade foi obrigada a desocupar.

Quase que desprovidos de condições para a produção e reprodução da vida em comunidade (pois as terras que Ihes restaram mal davam para isso), muitos descendentes de Benedito Fortunato, incluindo filhos(as), netos(as) e bisnetos(as), viram-se obrigados a buscar outra alternativa de vida em Veredinha ou algum outro lugar - especialmente São Paulo, Paraná e Minas Gerais?.

Esse êxodo, de acordo com as informações coletadas na pesquisa de campo, pode ser confirmado pelas 28 unidades residenciais, que viviam na comunidade em 2015, e atualmente pelas 32 que continuam lutando para permanecer, produzindo e morando no território que Ihes restou. Antes da desterritorialização, ocorrida em 1990, a quantidade de famílias era de setenta e duas (75), ou seja, esse processo provocou uma redução de cerca de $57 \%$ das famílias que compunham a comunidade antes do processo de desterritorialização.

A luta pela permanência no território é traduzida como ato de resistência e disposição à luta dos moradores de comunidades quilombolas, visto que o poder público é muito lento na garantia e preservação dos direitos de posse territorial dessas comunidades. A resistência, dos quilombolas de Velame, ao processo de desterritorialização contou tanto com a contratação de advogado - para restabelecer a verdade da compra e venda das terras da fazenda Velame-como com a plantação de roçados em áreas consideradas como de posse irregular do fazendeiro Josefino Ferraz.

Em entrevistas e pesquisa de campo realizadas na comunidade em questão, notamos que essas formas de resistência são marcadas por muita desilusão e sentimento de impotência frente ao poderio econômico dos fazendeiros da

9Trecho da Entrevista com Informante idoso, Comunidade de Velame, 2015. 
região. De acordo com o Relatório Antropológico da Comunidade Quilombola de Velame (2009), os advogados que assumiam a causa da comunidade foram, sistematicamente, aliciados e/ou desencorajados a continuar à frente do processo em defesa da comunidade.

A letargia do poder público, em dar celeridade ao processo de titulação das terras quilombolas, associado à forte repressão policial, fez que que aumentasse o desânimo e o sentimento de impotência dos quilombolas de Velame e, com medo de perder até mesmo o pouco de terra que lhes restou, muitos passaram a vender suas porções de terras para os fazendeiros da região.

De maneira geral, o processo de desterritorialização dos quilombolas de Velame ocorreu de 1940 a 1990, ano em que, por meio de uma liminar de "reintegração de posse" - que afirmava serem de Josefino Ferraz os sessenta (60) alqueires de terras - o fazendeiro expulsou, usando força policial, toda a comunidade da área que ainda ocupava na Fazenda Velame10. De acordo com a memória dos moradores mais antigos da comunidade, o episódio da desterritorialização é descrito de seguinte maneira:

Aí deu seis alqueire pro coronel da Polícia Militar e aí a polícia, como ela ganhou terra de graça, logo ela vai. Aí a juíza foi e autorizou. Quando a juíza autorizou ele veio, o coronel veio, e junto com uma D-20 cheia de polícia, 10 polícia; daí nóis ia fazer o quê? Nada. Chegou tudo armado (meio dia), chegou e quebrou as casa tudo e nóis fiquemo. Pegô e botô, tinha a minha sogra umas galinha ali oh, botou fogo no ninho de galinha que quebrava o ovo, o ovo pocava, a galinha choca deitada pocava igual a pipoca no fogo. E aí quebrou tudo e aí foi embora. Aí eles, de tarde, panhô o povo tudo, quebrou as casa, derrubou tudo casa de enchimento; hoje não, essas casa aqui de cimento, batia pau assim igual...né. Aí a polícia foi e ficou aqui dentro rodando aqui oh. Fechô a cancela lá em riba, trancou com...botou um cadeado e ficou aqui a polícia rodando" ${ }^{1}$.

Pela descrição podemos notar a violência com que ocorreu a desterritorialização final da comunidade, expulsa de suas terras sem direito a qualquer defesa, sem nenhuma notificação prévia da justiça, quanto a decisão

10RELATÓRIO ANTROPOLÓGICO DA COMUNIDADE QUILOMBOLA DE VELAME, 2009.

"Trecho da Entrevista com Informante idoso, Comunidade de Velame, 2015. 
da juíza, à comunidade. Ou seja, foram todos pegos de surpresa, com os homens trabalhando em suas roças e só tendo sua atenção atraída a partir dos gritos de indignação e violência de suas famílias durante a expulsão. Ainda de acordo com o informante, citado acima, todos os bens que pertenciam à comunidade, tais como documentos, móveis, utensílios domésticos, roupas etc., foram carregados num caminhão e levados, sob custódia da Polícia Militar, para um galpão na cidade de Veredinha. Após a apreensão dos pertences dos moradores, todas as residências foram demolidas e os materiais destruídos para evitar que os moradores reaproveitassem o material da demolição para reerguer as casas. Para finalizar a desocupação, com suas casas já destruídas, os quilombolas foram colocados em fila e obrigados a saírem da terra ${ }^{2}$. Assim descreve o processo de expulsão de suas residências uma das nossas informantes, que estava na comunidade naquele momento:

É porque quando foi naquela época aí eles já chegaram, eles não mandaram avisar pro pessoal sair não, eles já chegaram com a polícia já derrubando as casa em cima até das pessoas que tava fazendo almoço, já foi derrubando tudinho em cima de tudo eles, não chegaram e mandaram assim: ah, você vai ter que sair. Não. Já chegaram derrubando tudo. Jogando as coisas lá pra fora e os outros que tava dentro de casa, uma equipe já veio derrubando tudo. Foi muito triste ${ }^{13}$.

Ainda de acordo com essa informante, no momento em que a polícia iniciou a ação nas casas os homens estavam trabalhando na roça, achando-se nas residências apenas mulheres, crianças e idosos(as): "eles já chegou e derrubou tudo em cima que tava cozinhando, já foi derrubando tudo, as telha tudo em cima do fogão. Já foi jogando tudo, tudo que eles pegava já foi jogado pra fora".

Consolidada a desterritorialização, muitos foram procurar abrigo junto aos seus parentes (também expulsos de Velame na década de 1940) e vizinhos em Veredinha. Outros conseguiram abrigar-se nas comunidades quilombos da região (Lagoa de Melquíades, por exemplo) e outra parcela de desabrigados dirigiu-se para Vitória da Conquista ou outras cidades e estados do país, em busca de trabalho, moradia e sustento para os seus familiares. Portanto, a Comunidade 
Quilombola de Velame passou por dois momentos de expulsão de suas terras que deixaram marcas muito profundas na mesma, a saber, um em 1940 e outro em 1990.

Mesmo diante de todas as dificuldades enfrentadas com a expulsão do seu território, os moradores da Comunidade Quilombola de Velame continuaram buscando uma maneira de retornar e, por meio da sua Associação de Moradores, solicitaram a ajuda de um advogado, junto ao Sindicato dos Trabalhadores Rurais. Paulo de Tarso, mesmo sabendo que a comunidade não tinha condições de pagar seus honorários, foi o advogado que passou a representar a comunidade e, assim que assumiu a causa, solicitou e conseguiu, junto ao judiciário, a derrubada da liminar de reintegração de posse que havia sido concedida em favor de Josefino Ferraz. Um morador antigo assim resumiu o período em que a comunidade ficou sem o seu território e o retorno para o mesmo após a cassação da liminar que motivou a expulsão:

Aí nóis fiquemo lá fora, todo mundo foi caçar cuidar da vida, uns não tinha nem lugar pra ficar, o outro ficou na casa da avó daquele alí porque não tinha lugar pra ficar, foi qui...até que deus ajudô que deu dois ano, dois ano e meio, eles desembargaram e mandou nóis retornar à terra. Foi que nóis entremo, vortemo pra dentro de novo e daí em diante, graças a deus, não saímos mais, né. Mais foi uma luta meia pesada pra nós ${ }^{14}$.

O ano de 1992 representou um momento de relativo alívio para a comunidade, que viu nesse gesto da justiça a possibilidade real de regressarem para as suas terras de ocupação tradicional. Porém, essa felicidade ficou incompleta na medida em que apenas uma pequena parcela das terras foi devolvida à comunidade, permanecendo em posse de Josefino Ferraz a maior parte delas. Afora isso, a comunidade não contou com nenhuma ajuda para a reconstrução das casas que haviam sido derrubadas em 1990, por conta do violento processo de expulsão dos moradores.

Todos os equipamentos para o trabalho na lavoura, que haviam ficado sob custódia da Justiça, em Veredinha, também não foram devolvidos à

14Trecho da Entrevista com Informante idoso, Comunidade de Velame, 2015. 
comunidade15, ou seja, embora tenha sido muito importante o retorno para suas terras, o poder público não ofereceu qualquer tipo de ajuda para a retomada da vida na Comunidade, deixando a mesma à sua própria sorte.

O momento do retorno configurou-se como um marco importante para a comunidade, na luta pelo território que fora expropriado, já que uma parte dos moradores pôde regressar às suas terras e reconstruir suas vidas. Após ter conseguido a cassação da liminar o advogado da Comunidade passou a causa para Délcio Medeiros que, diante das dificuldades apontadas pelas famílias sobre - tamanho insuficiente das terras para acomodar a comunidade, sugeriu um acordo judicial entre os quilombolas e o fazendeiro, que fora aceito por ambas as partes.

Por este acordo, foi reconhecido aos quilombolas uma área de 21,5 alqueires, enquanto que o restante da área em litígio ficou com o fazendeiro. Ocorreu que, desses vinte e um alqueires e meio, a comunidade doou meio alqueire a Maria de Lurdes Duarte, em sinal de agradecimento pela ajuda que dela recebera quando da expulsão de suas terras. O restante das terras foi registrado, de forma coletiva, em favor de Osvaldo Fortunato da França, Lúcio Fortunato da França, Agenor Fortunato da França, Florentino Barbosa dos Santos, Acilínio Ferreira dos Santos, Donatílio Ferreira dos Santos, Manuel Moreira dos Santos, Aluízio Alves Lemos, Ivandro Custódio da Silva, Ocremício Fortunato Gonçalves, Joaquim Ferreira dos Santos, José Ferreira dos Santos, Aécio de Jesus França, Maria de Jesus França, Cecília Maria dos Santos, e Carmelita França de Souza'b.

Embora os 21 alqueires de terra tenham sido registrados de forma coletiva, em nome dos 17 descendentes de Benedito Fortunato da França, Délcio Medeiros (advogado da comunidade) solicitou e conseguiu, como pagamento dos honorários advocatícios, quatro (4) alqueires. Sem condições materiais para reconstruir tudo o que havia sido destruído durante o processo de expulsão das terras, alguns quilombolas acabaram vendendo para Délcio Medeiros três (3) alqueires de terra. Ou seja, dos 21 alqueires conquistados pela comunidade no acordo com o fazendeiro Josefino Ferraz, apenas 14 ficaram, efetivamente, à

15RELATÓRIO ANTROPOLÓGICO DA COMUNIDADE QUILOMBOLA DE VELAME, 2009. 16RELATÓRIO ANTROPOLÓGICO DA COMUNIDADE QUILOMBOLA DE VELAME, 2009. 
disposição da comunidade para sua produção e reprodução' ${ }^{17}$.

A questão a ser levantada, neste caso, é a seguinte: se este pedaço de terra foi registrado de forma coletiva, como poderiam os herdeiros de Benedito Fortunato da França venderem alguns pedaços? Em relação a esta discussão, a argumentação de Bandeira (1991, p. 09) dá-se no sentido de reforçar que a terra, nas comunidades quilombolas, é coletivamente apropriada pelos moradores da comunidade e, assim, acaba se configurando como "um bem público das comunidades negras". No contexto em que a Comunidade Quilombola de Velame conseguiu recuperar uma parte de suas terras, início da década de 1990 , - INCRA - e esta é uma crítica da autora - reconhecia a posse privada das terras dessas comunidades, o que acabou gerando um enorme problema para as próprias comunidades, na medida em que este posicionamento acabava esvaziando aquele sentido original da terra, qual seja o de bem público a ser partilhado e compartilhado no interior da comunidade.

Portanto, se associarmos a ausência de qualquer auxílio (município, estado e União) - que pudessem auxiliar os quilombolas de Velame a reconstruírem suas casas e seus roçados - com essa postura do INCRA compreenderemos um pouco mais o êxodo de algumas famílias, alguns anos após terem conseguido voltar para as terras da comunidade. A princípio, parece que uma parte dos herdeiros de Benedito Fortunato da França se relacionava com a terra como se ela fosse uma propriedade privada, uma herança do seu ancestral que poderia ser negociada no momento em que assim o desejasse.

\section{De comunidade negra rural à comunidade negra rural quilombola: políticas públicas, desenvolvimento social e adiamentos}

A afirmação da identidade nas comunidades negras rurais passa pelo valor da terra e pela especificidade de suas expressões culturais (GLORIA MOURA).

Nas discussões sobre o termo quilombo, realizadas por vários autores, tais como Alecsandro Ratts (2012), Abdias do Nascimento (2002), Clóvis Moura (2001),

17RELATÓRIO ANTROPOLÓGICO DA COMUNIDADE QUILOMBOLA DE VELAME, 2009. 
Beatriz Nascimento (1985), Lélia Gonzalez, Joel Rufino dos Santos, José Maurício Arruti (2003), Alfredo W. B. Almeida (2002), etc., notamos que o elemento comum às definições é que procuravam superar a ideia, do passado, de redutos de fugitivos, dando ênfase ao resgate da liberdade e da dignidade por meio da organização de uma sociedade livre, praticante de policultura e com algumas desigualdades sociais.

De certa forma, essa linha de argumentação em torno da definição do que seria quilombo remete-nos às considerações de Bhabha (1998), quando este autor apresenta sua noção de hibridismo. Ao se concentrar na relação entre discurso e poder, ele se coloca preocupado em compreender os espaços de enunciação evidenciados no entremeio das fronteiras que definem a identidade coletiva. $O$ autor nos sugere que a ideia da diferença é construída pelo fluxo de representações, que são articuladas externamente e, por isso mesmo, o sujeito não pode ser definido pelo lugar que ocupa na estrutura social, mas antes devemos tratá-lo sempre como um sujeito provisório, circunstancial, reflexivo. O conceito de diferença, neste autor, está ligado aos processos de hibridização (inscrição e reinscrição), que fogem ao controle do(s) ator(es), pois a ênfase está no processo e não no sujeito.

Esta consideração do autor nos leva a observar que o conceito de quilombo, assim como o de quilombola, jamais poderá ser tratado a partir de essencialismos, ou categorias fixas e imutáveis no tempo e no espaço, ou seja, reforça-nos a ideia de que os sentidos do termo quilombo ou quilombolas (urbanos ou rurais) devem ser buscados na dinâmica atual dessas comunidades, que estão em constante processo de mudança. Nesse sentido, podemos afirmar que a noção de hibridismo do autor nos permite operar dois movimentos, um desconstrutivista, que desmonta a possibilidade de um lugar de enunciação homogêneo, e outro normativo, que define uma condição global cosmopolita (referência a uma cultura e a um mundo híbridos) - ecumene mundial acima de raça, nação, etnicidade, etnia, etc.

Uma outra chave de discussão importante pra entendermos a transição de comunidade negra rural pra comunidade rural quilombola é a proposta por Hall (2000), num texto intitulado Quem precisa de identidade. Nesse texto, Hall propõe uma intensa discussão acerca do tema identidade, indicando que precisa de 
identidade aqueles que necessitam de poder e, nessa trajetória, as pessoas escolhem o lado que as aproxima do poder. Sua discussão sobre o conceito de identidade não é essencialista, mas antes um conceito estratégico e posicional. Essa discussão sugere que, na modernidade tardia, as identidades são, cada vez mais, fragmentadas, fraturadas, multiplamente construídas. Com isso, Hall evita que se compreenda o conceito de identidade como se fosse algo imutável, singular, fixo no tempo e no espaço. E é justamente isso que nos ajuda a compreender a incorporação da identidade quilombola pelos moradores de Velame, pois na relação com o Estado uma identidade quilombola permite que a comunidade passe a acessar as políticas públicas voltadas a esse segmento da população, caracterizando um movimento tático e estratégico fundamental para que seus membros possam, individualmente e/ou como grupo, ser reconhecidos na relação com outros grupos e setores da sociedade brasileira.

É no sentido da discussão, proposta tanto por Bhabha (1998) como por Hall (2000), que discorreremos sobre a transição, ocorrida em Velame, de comunidade negra rural para comunidade rural quilombola. Essa transição ocorre a partir do momento em que a comunidade vislumbra alguns ganhos, ao assumir uma nova identidade, e no caso de Velame essa inflexão ocorreu justamente quando a comunidade passou a ter contato com pessoas / de fora da comunidade, mais precisamente com alguns membros do Movimento Negro do município de Vitória da Conquista, que Ihes explicaram as políticas que a comunidade poderia acessar caso passasse a se autodefinir como quilombola ${ }^{18}$.

Após sua certificação, ocorrida em 19/04/2005, a Comunidade Quilombola da Velame, começou a ser beneficiada com algumas ações do estado. A primeira ação estatal de impacto na comunidade foi a chegada da energia elétrica, por meio do Programa Luz para Todos (2006/07) que, além da iluminação, permitiu à comunidade utilizar equipamentos acionados pela energia elétrica. Na sequência, entre 2006 e 2008, a comunidade recebeu a Assistência Técnica e Extensão Rural (ATER), assessoria ligada ao Ministério do Desenvolvimento Agrário (MDA). No ano de 2014 a comunidade foi beneficiada com: 1) a inauguração de um Posto de Saúde da Família, sendo a equipe composta por uma agente de saúde (moradora

${ }^{18}$ RELATÓRIO ANTROPOLÓGICO DA COMUNIDADE QUILOMBOLA DE VELAME, 2009. 
da própria comunidade), uma enfermeira e uma médica cubana; 2) a canalização de água potável para o atendimento de toda a comunidade, feita graças à Companhia de Engenharia Ambiental e Recursos Hídricos da Bahia (CERB), vinculada à Secretaria do Meio Ambiente e Recursos Hídricos.

Em 2016, por meio da Companhia de Desenvolvimento e Ação Regional (CERB/BA - ligada à SEDIR), a comunidade recebeu um trator e equipamentos agrícolas para uso compartilhado com mais três comunidades quilombolas, a saber, Lamarão, Lagoa de Melquíades e Baixa Seca. Por fim, em 2016 a comunidade ingressou com uma solicitação, junto à Companhia de Desenvolvimento e Ação Regional (CAR/BA), para a construção de 16 unidades Habitacionais. A comunidade havia conseguido verba para a construção das unidades, junto ao governo federal, porém, foi liberada apenas uma parte, suficiente para a construção de 8 unidades, sendo o restante da verba cancelada pelo governo federal. Por fim, desde dezembro/2019 a comunidade conta com uma Unidade de Beneficiamento da Mandioca (principal produto da agricultura de Velame), que também beneficia a produção de mandioca de mais duas comunidades quilombolas, a saber, Baixa Seca e Lagoa de Melquíades.

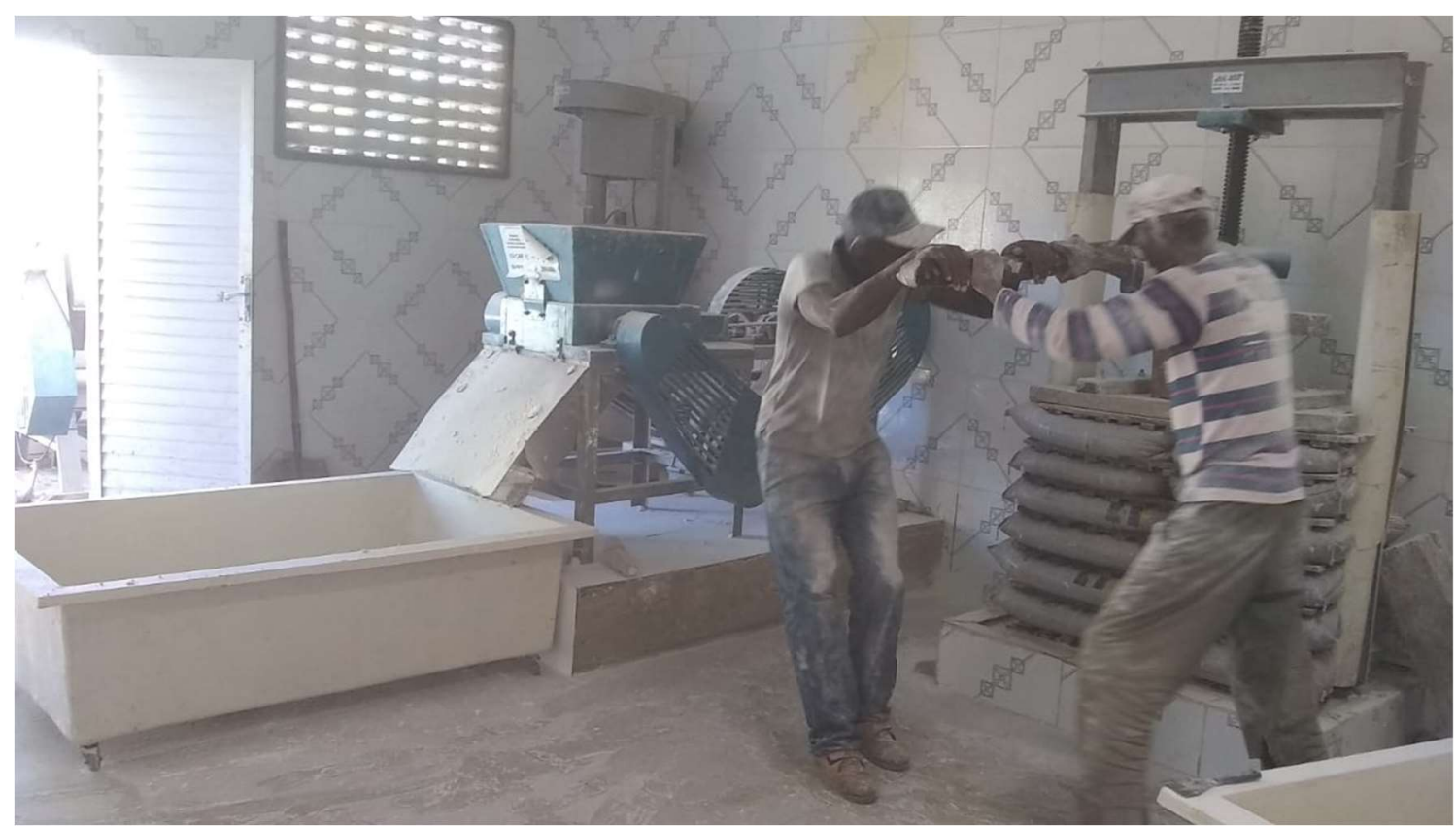

Figura 2: Unidade de Beneficiamento da Farinha da Comunidade Quilombola de Velame, Bahia.

Fonte: Fota cedida por Marinaldo Carvalho dos Santos, 2020. 
Buscando construir uma maneira de enfrentamento das dificuldades sentidas e uma melhor organização dos agricultores familiares - que trabalham a cadeia produtiva da mandioca, café, fruticultura, horticultura, avicultura e artesanato -, as comunidades quilombolas de Velame, Cachoeira do Rio Pardo, Baixa Seca e Lagoa de Melquíades, estão juntando documentos para a fundação da COOMAFAQ (Cooperativa Mista de Agricultores Familiares Quilombolas), tendo como eixo de trabalho/atuação a assistência técnica, comercialização e unidade de beneficiamento 19 .

Essas ações, que chegaram até a comunidade, sugerem haver certo nível de cooperação entre as três esferas do poder público (municipal, estadual e união), e certamente foram de grande importância para a garantia de melhores condições de vida, embora ainda insuficientes.

A autodefinição tem sido estratégica para as comunidades quilombolas espalhadas pelo território nacional, pois além do acesso as políticas públicas, ela ainda deveria facilitar o processo de recuperação do território original. De posse da Certificação, emitida pela Fundação Cultural Palmares, a comunidade fica habilitada a solicitar a abertura do processo de reconhecimento e demarcação do seu território junto ao INCRA20.

Embora a expectativa gerada tenha sido grande, notamos, pela fala de alguns membros da comunidade quilombola em estudo, que o acesso à direitos continuou chegando lentamente e isso dificultava, sobretudo, a permanência da juventude na comunidade. No fragmento a seguir apresentamos o trecho da fala de um morador dessa comunidade, quando questionado sobre o que havia mudado na comunidade após a mesma se autodefinir como quilombola.

Pra mim não mudou nada, porque nós continua quase na mesma, só mudou na fala. Porque não temos nada com os nossos direitos, como eles falava né, e fala até hoje como direito, depois de sair temos direito a receber recurso, poder trabalhar. Mas até hoje, sinto como quilombo, mas sem nada. E a cada vez mais apertando porque, cê sabe, a gente foca numa coisa, pensando

\footnotetext{
19Trecho da Entrevista com Informante adulto, Comunidade de Velame, 2015.

${ }^{20} \mathrm{~A}$ Posse Coletiva da terra é fundamental para as comunidades quilombolas (assim como para todos os povos tradicionais), na medida em que impede a comercialização de qualquer parte da propriedade demarcada e titulada pelo INCRA ou por algum órgão estadual. Trecho da Entrevista com Informante idoso, Comunidade de Velame, 2015.
} 
que aquela coisa vai adiante, depois a gente vê a coisa voltando pra trás e não pode né, as coisas têm que ser pra frente. Porque no começo tava aquilo avançando, os jovens tava tudo junto pensando que aquilo saía pra eles poder ficar aqui dentro, trabalhar; que as coisas tá difícil. Aqui dentro a terra é pequena e também recursos né. Aceitar como Quilombo pra você ter o direito de chegar, mesmo que não tenha um projeto do governo dando, mas ao menos emprestando pra pagar depois ${ }^{21}$.

Nesse trecho o informante destaca que a transição de uma identidade para outra não surtiu o efeito esperado pelos moradores, sobretudo porque a expectativa, ao assumir uma identidade quilombola, era de que a vida na comunidade se tornasse muito melhor. No relato é revestido de muita angústia e frustração em relação às políticas públicas que, na sua visão, estão chegando de forma muito lenta até a comunidade.

A falta de recursos e de um profissional para ajudá-los a trabalhar a terra, de forma a torná-la produtiva, é uma reclamação constante em quase todas as entrevistas que realizamos na comunidade. Ainda de acordo com os moradores, quando recorrem aos Bancos solicitando empréstimos, para serem aplicados na produção agrícola, Ihes é negado com a justificativa de que a comunidade não possui condições de oferecer garantia de pagamento junto à instituição financeira. Dados do Ministério do Desenvolvimento Agrário (2012) ilustram essa dificuldade, uma vez que apontam que a agricultura familiar22 fica com apenas $14 \%$ do crédito para financiamento da produção agrícola - o agronegócio acesso os outros $86 \%$ - numa porção de $24 \%$ das terras agricultáveis do Brasil, enquanto o agronegócio ocupa $76 \%$ dessas terras.

A parte final da fala do informante idoso, citado acima, explicita o que certamente seja o maior problema enfrentado pela comunidade quilombola de Velame, qual seja, um território insuficiente para garantir a produção e a reprodução da vida social do grupo. Essa insuficiência acaba diminuindo as expectativas da juventude no tocante à permanência na comunidade.

Nessa comunidade, as famílias que cultivam a terra dependem da mão de

\footnotetext{
${ }^{21}$ Trecho da Entrevista com Informante idoso, Comunidade de Velame, 2015.

22 De acordo com a Lei n. 11.326/2006 são considerados agricultores familiares: silvicultores, aquicultores, extrativistas, pescadores, indígenas, quilombolas e assentados da reforma agrária
} 
obra familiar, incluindo os braços da juventude e, por essa razão, o êxodo desse segmento provoca tanta angústia e preocupação. Alguns moradores mais velhos da comunidade demonstraram sua angústia em não poder contar com toda a força da família para a agricultura, visto que muitos jovens têm abandonado a vida na comunidade e ido tentar melhor sorte nas cidades. Essa preocupação, de êxodo da comunidade, é reafirmada pelo trecho da fala de uma informante que destacamos a seguir.

eu espero que a gente melhore né, a expectativa de vida. Porque a tendência da gente é ir ficando só mais velho, o tempo vai passando e a gente ficando mais velho e se as coisa não ir melhorando só vai dificulta mais ainda. [...] Tem muitos que já saem pra fora porque não tem aquela condição de ficar na comunidade, direto ali, porque a renda é pouca. As vezes quer crescer na vida, mas não tem como né23.

É destacado que, embora reconheçam a importância dos estudos, a continuidade dos mesmos tem sido prejudicada pelo fato da prefeitura municipal de Vitória da Conquista/BA ter deixado de oferecer transporte ou passe escolar para o deslocamento até os colégios da cidade. Por esta razão, muitos acabaram desistindo dos estudos entre a quinta e sétima série do Ensino Fundamental.

De acordo com a Secretaria Estadual de Educação (SEI) da Bahia ${ }^{24}$, o Estado tem reduzido o analfabetismo, entre 2007 e 2013, sendo que no meio urbano essa taxa caiu de $12,2 \%$ para $10,4 \%$, enquanto que no meio rural a queda foi de $32,1 \%$ para 28,3\%. A taxa geral de analfabetismo na comunidade Quilombola de Velame, segundo dados disponibilizados pela SEPPIR, é de $40 \%$, índice extremamente elevado, considerando que a comunidade está inserida numa das regiões mais dinâmicas do estado da Bahia.

De maneira geral, as reclamações dos moradores de Velame podem ser resumidas, basicamente, em dois pontos umbilicalmente interligados. O primeiro consiste no fato das terras, para produção agrícola da comunidade, serem insuficientes para suprir até mesmo as necessidades internas das famílias que

23Trecho da Entrevista com Informante jovem, Comunidade de Velame, 2015.

24 Com base nos dados sobre Educação da Pesquisa Nacional por Amostra de Domicílios (PNAD/IBGE). 
atualmente residem no quilombo, enquanto o segundo refere-se às dificuldades de acessar as políticas públicas voltadas à produção agrícola. Dividindo-se os 14 alqueires de terra pela quantidade de famílias que atualmente residem na comunidade (32 famílias), chegaremos à conclusão de que cada unidade familiar dispõe de menos de meio alqueire de terras para produzir e atender as suas necessidades de subsistência.

De acordo com o Coordenador da Associação dos Moradores de Velame, existem muitos dos seus parentes que desejam voltar a viver na comunidade, mas $80 \%$ das terras da mesma estão nas mãos dos fazendeiros da região. Portanto, a dificuldade em obter a titulação das terras traz enormes problemas de produção e reprodução à comunidade, que devem ser pensados muito além da capacidade produtiva da mesma. Ou seja, sem a demarcação do território os antigos moradores de Velame, ou seus descendentes diretos, que desejam viver na comunidade, acabam impedidos de fazer esse caminho de volta.

Em relação à demora na titulação das terras da comunidade, um dos seus moradores aponta outro problema que a mesma irá enfrentar quando, enfim, a titulação do território for feita, qual seja, o desmatamento das terras da comunidade que estão sobre o controle dos fazendeiros da região.

E os fazendeiros aí, no caso, eles não são besta, sabem que a terra pra muitos deles aí, que ela é do INCRA - porque quando é titulada e tudo o INCRA já fez um trabalho Federal - é terra do governo. Quer dizer, é nossa no caso de querer ficar, mas depois que titular aí ela passa a ser da União. Então, no caso aí os ricos aí já sabe, quando eles não consegue vender ela pra ganhar verba ou investimento, eles começa a destruir o que tem. Aí tinha reserva, eles vão cortando tudo o que era reserva eles mata. Aí mesmo tinha o resto aí que eu ouvi falando que o cara tava até fazendo carvão, vendeu pra outro... tudo é agora de um ano pra cá, por que ali ele tem o direito de vender, que o INCRA deixou bem claro que ninguém tem nada a ver. É direito deles, só depois que o governo pagar ${ }^{25}$.

Pelo trecho anterior, nota-se a preocupação da comunidade com o estado

25 Trecho da Entrevista com Informante Membro da Associação dos Moradores, Comunidade de Velame, 2015. 
em que estará a terra, quando esta voltar a lhe pertencer, pois a terra é vista como elemento central para produção e reprodução da comunidade. Nesse sentido, uma terra fraca, e com baixa ou nenhuma produtividade, terá pouca serventia para o fortalecimento e crescimento dessa comunidade quilombola. No Relatório Antropológico da Comunidade Quilombola de Velame (2009) essa preocupação já apareceu quando os moradores mais antigos falavam da rotatividade das áreas de roçados, para o descanso da terra, e da conservação das matas de cipó nativas - fundamentais para garantia da caça, da lenha para cozinhar, das ervas e folhas medicinais, e para a preservação dos "olhos d'água".

$\mathrm{Na}$ literatura especializada sobre comunidades quilombolas, existe um consenso sobre a função estratégica que o território possui, tanto para a continuidade do grupo (produção e reprodução) como para a valorização da cultura, pois o território se constitui num "espaço comum, ancestral, de todos que têm os registros da história, da experiência pessoal e coletiva do seu povo" (BRASIL, 2005 , p. 49). A terra - enquanto local de nascimento, trabalho e sociabilidades caracteriza-se como espaço de encontros e interações intra e Inter geracionais, no qual passado, presente e futuro são compartilhados cotidianamente, seja pela familiaridade ou pela consanguinidade.

O segundo ponto, referente às reclamações da comunidade, está na dificuldade de acesso às políticas públicas que poderiam potencializar a produção agrícola no interior da comunidade. Com relação a este aspecto, assim afirma o coordenador da Associação dos Moradores de Velame:

Eu trabalho com mandioca, feijão, mexo com a horta, mas não tenho muito apoio pra produzir porque às vezes a gente não tem condições de trabalhar assim com irrigação, então não tendo apoio muito a gente trabalha, vendo às vezes alguma coisa, mas é bem difícil26.

Com cada família tendo que retirar seu sustento a partir de uma pequena faixa de terras, o descanso da mesma fica quase impossível, e a consequência desse esgotamento do solo é a baixíssima produção por unidade familiar. Como

26 Trecho da Entrevista com Informante Membro da Associação dos Moradores, Comunidade de Velame, 2015. 
se trata de uma terra explorada à exaustão, pelo fato de não haver espaço para o descanso da terra, parece razoável que uma ajuda, por parte do poder público, no sentido de garantir infraestrutura para a produção, seria fundamental para que houvesse uma melhora nas condições de produção do solo que atualmente cabe a cada uma das famílias que lá residem.

Grosso modo, essas duas grandes dificuldades, apontadas, deságuam em apenas uma, a saber: a demora na titulação das terras da comunidade, procedimento este que certamente ampliaria as áreas de agricultura e criação de pequenos animais e, por sua vez, garantiria a sustentabilidade no interior da comunidade e aumentaria a quantidade de seus moradores.

\section{Considerações Finais}

As discussões aqui realizadas procuraram apontar a trajetória da Comunidade Quilombola de Velame, marcada por momentos de tranquilidade, paz e harmonia, até o falecimento do seu fundador, e momentos de intensas agressões, desarticulação, lutas pela reconquista de seu território original e pela letargia do Estado brasileiro em garantir o cumprimento da Constituição Federal de 1988.

A luta por seus direitos de propriedade se traduz no direito a continuar existindo diante de um estado que possui enormes dificuldades em fazer valer artigos constitucionais, assim como resoluções internacionais. Grosso modo, a CF de 1988 criou um conjunto de desafios ao Estado brasileiro, pois avançou no reconhecimento dos direitos numa velocidade superior à compreensão dos operadores da justiça, daí os processos de titulação dos territórios quilombolas ultrapassarem 15 anos. No caso da Comunidade Quilombola de Velame o processo se arrasta por 16 anos, sem nenhuma perspectiva de titulação junto ao atual governo.

O contato com integrantes do Movimento Negro de Vitória da Conquista permitiu à comunidade tomar contato com um conjunto de políticas públicas que a mesma poderia acessar, caso assumisse uma identidade quilombola. Portanto, a transição para uma identidade negra rural quilombola ocorreu a partir de uma 
leitura estratégica que a comunidade fez, para poder reconquistar suas terras e acessar as ações (União, estados e município) capazes de garantir, num primeiro momento, a permanência de seus membros no interior da comunidade e, posteriormente, a volta daqueles que não haviam conseguido retornar durante o processo de reterritorialização, ocorrido em 1992. Depois que se autodefiniu como quilombola, a comunidade passou por algumas importantes mudanças, tais como o recebimento da luz elétrica, água encanada, construção da Casa da Farinha, recebimento de um trator e equipamentos agrícolas, além do cadastramento das famílias no Programa Bolsa Família. Porém, a comunidade se ressente de mais atenção, especialmente no que se refere a trabalho e renda, capazes de absorver não apenas a população adulta da comunidade, mas sobretudo a sua juventude e, com isso, manter as novas gerações trabalhando e vivendo na comunidade.

Nesse sentido, pudemos compreender que a terra, associada às políticas públicas, é fundamental para a manutenção e o fortalecimento da identidade quilombola na Comunidade Rural de Velame. É a partir desses dois elementos conjugados que a comunidade passou a ter condições de pensar e discutir 0 modelo de desenvolvimento desejado.

Pra finalizar, gostaríamos de destacar que a titulação das terras quilombolas é condição fundamental para que essas comunidades possam ter continuidade existencial, produzindo seus roçados e vendendo no comércio local. A titulação da terra mostra-se importante para garantir a reprodução da vida nessas comunidades, especialmente para que a juventude possa dar continuidade aos roçados, festividades religiosas, etc.

\section{REFERÊNCIAS BIBLIOGRÁFICAS}

ALMEIDA, Alfredo W. B de. Quilombos: sematologia face a novas identidades. In SMDDH; CCN. (Org.) Frechal Terra de Preto: quilombo reconhecido como Reserva Extrativista. São Luís, 1996 p. 11-19.

Os Quilombos e as Novas Etnias. In: O'Dwyer, Eliana C. (Org) Quilombos: identidade étnica e territorialidade. Rio de Janeiro. Editora FGV, 2002 p.43-81. 
ARRUTI, José Maurício A. P. A Emergência dos 'Remanescentes: notas para O dialogo entre indígenas e quilombolas. MANA 3(2), 1997. p. 7-38. DOI: https://doi.org/10.1590/s0104-93131997000200001

O quilombo conceitual: para uma sociologia do artigo 68 do ADCT. In: Relatório técnico-científico sobre os remanescentes da Comunidade de Quilombo de Cangume, município de Itaóca/SP. ITESP, setembro de 2003. 191 p.

BHABHA, Homi K. O local da cultura. Trad. Myriam Avila Eliana Lourenço de Lima Reis e Gláucia Renata Gonçalves. Belo Horizonte: Editora UFMG, 1998.

BRASIL. Secretaria Especial de Políticas de Promoção da Igualdade Racial. Programa Brasil Quilombola. Brasília, DF: SEPPIR, 2005.

BRASIL. [Constituição (1988)]. Constituição da República Federativa do Brasil: texto constitucional promulgado em 5 de outubro de 1988, com as alterações adotadas pelas Emendas Constitucionais n os 1/1992 a 68/2011, pelo Decreto Legislativo no 186/2008 e pelas Emendas Constitucionais de Revisão n os 1 a 6/1994. - 35. Ed. Brasília: Câmara dos Deputados, Edições Câmara, 2012. 454 p. - (Série textos básicos; n. 67).

CONCEIÇÃO, Silvano da. Estratégias de permanência e desenvolvimento social na Comunidade Rural Quilombola de Velame, Bahia. Tese de Doutorado - São Carlos, 2016. $225 \mathrm{p}$.

HALL, Stuart. A Identidade Cultural na Pós-Modernidade. Rio de Janeiro: DP\&A Editora, 2000.

. Quem precisa de identidade? In: Identidade e Diferença: a perspectiva dos estudos culturais. Trad. Tomaz Tadeu da Silva. Petrópolis: Vozes, 2000.

. Da diáspora: identidades e mediações culturais. Editora UFMG, 2003. 
INCRA. Relatório Antropológico da Comunidade Quilombola de Velame. Brasília, 2009.

SANCHEZ, Fábio José Bechara. Identidade e Conflito: a construção política dos "remanescentes de quilombo" do Vale do Paraíba. 2004. 158 f. Dissertação (Mestrado em Sociologia), Programa de Pós-Graduação em Sociologia. Universidade de São Paulo. São Paulo, 2004. 158 p.

Silvano da Conceição: Doutorado em Sociologia pela Universidade Federal de São Carlos (2016). Possui Mestrado em Ciências Sociais (com ênfase em Relações Sociais, Poder e Cultura) - 2004 - e Graduação em Ciências Sociais - 2000 -, ambos pela Universidade Federal de São Carlos. Foi Coordenador do Subprojeto Interdisciplinar do Programa Institucional de Bolsas de Iniciação à Docência com Linha de Ação em Educação do Campo, em convênio com a Comissão de Aperfeiçoamento de Pessoal de Nível Superior (PIBID UESB/CAPES). Atualmente é professor Adjunto B da Universidade Estadual do Sudoeste da Bahia. Tem atuado nos seguintes temas: comunidades quilombolas, diversidade étnica, educação, políticas públicas e identidade.

cC) This work is licensed under a Creative Commons Attribution 4.0 International License.

(c) Este trabalho está licenciado com uma Licença Creative Commons - Atribuição 4.0 Internacional.

Artigo recebido para publicação em: 09 de maio de 2020.

Artigo aprovado para publicação em: 17 de maio de 2020. 